\title{
Role of acidic pH of intravenous fluids in subsequent development of metabolic acidosis- may not be what it seems
}

\footnotetext{
Sir,

We extend our thanks to Singh et al. for drawing attention toward the controversies surrounding the use of acidic intravenous fluids (IVFs) infusion. ${ }^{[1]}$ They have rightly mentioned the propensity of 5\% dextrose (D5) and 0.9\% saline (NS) to cause thrombophlebitis and other deleterious effects. ${ }^{[1]}$ But unlike mentioned by the authors, current literature discusses the known and putative reasons for the $\mathrm{pH}$ of 5.5 of NS. ${ }^{[2]}$ Dissolved $\mathrm{CO}_{2}$ from atmosphere, the ionic composition of the solution and inherent properties of the packaging material in which the solutions are supplied, are thought to determine it. ${ }^{[2]}$ We believe that the same set of reasons may also explain the acidic $\mathrm{pH}$ (4.2) of D5.

Free acid activity is indicated by $\mathrm{pH}$ but the nondissociated acid molecules in a solution may not be characterized by the $\mathrm{pH}$ value. ${ }^{[2,3]}$ Thus solutions with high titratable acid have
} 
reservoir of hydrogen ion $\left(\mathrm{H}^{+}\right)$irrespective of $\mathrm{pH} \cdot{ }^{[3]}$ Citing the work of Gaudry et al. the authors attribute the acidity of IVFs to their method of sterilization, Gaudry et al. in their manuscript mentioned that the titratable acidity of majority of solutions under study (e.g. D5, NS) varied between 0.063 to 9.480 meq acid/l, depending on the method used for preparation and sterilization. ${ }^{[1,4]}$ Gaudry et al. also mention that though many have measured the $\mathrm{pH}$ of common IVFs, not much data are available regarding their titratable acidity ${ }^{[4]}$ The work of Gaudry et al. dates back to 1972 and a PubMed search by us with the term 'titratable acidity fluid/titratable acidity solution/titratable acidity infusion' revealed only two studies relevant to this discussion. These studies date back to 1973 and 2005 and only the abstracts could be retrieved by us. ${ }^{[3,5]}$ Though the in vitro $\mathrm{pH}$ of D5 and NS is acidic, their effect on $\mathrm{H}+$ balance is probably negligible. ${ }^{[2,4]}$ It may be because of their low titratable acid content. ${ }^{[4]}$ But metabolic acidosis accompanies infusion of these solutions. ${ }^{[1,2,4,6,7]}$ This acidosis was explained by dilution of bicarbonate content in plasma. ${ }^{[2,6,7]}$ Subsequently Stewart's physiochemical approach was used to describe the in vivo effect on acid base status by IVFs. ${ }^{[6,7]}$ According to the later concept, the acid-base effect of an IVF is determined by the strong ion deference (SID) and the total weak acid concentration ( $\mathrm{A}_{\mathrm{TOT}}$ ) of the fluid. ${ }^{[6,7]} \mathrm{pH}$ falls with decreasing SID, increasing $\mathrm{A}_{\mathrm{TOT}}$ or $\mathrm{CO}_{2 \mathrm{TOT}}$ (total $\mathrm{CO}_{2}$ content) $/ \mathrm{PCO}_{2} \cdot{ }^{[6,7]}$ As the IVFs equilibrate with ECF, they alter SID of ECF, as SID of these IVFs defers appreciably from that of plasma. ${ }^{[6,7]}$ SID of D5 and NS is 0, they decrease the SID of plasma and exert an acidifying effect. ${ }^{[6,7]}$ These crystalloids are devoid of any weak acids and decrease $\mathrm{A}_{\text {тот }}$ of plasma due to its diluting effect causing alkalosis. ${ }^{[6,7]}$ Whereas some colloids (e.g. albumin, gelatin) itself may contribute toward $\mathrm{A}_{\text {Tот }}$ of plasma, thus, acidifying it. ${ }^{[6,7]}$ Although $\mathrm{CO}_{\text {2тот }} / \mathrm{PCO}_{2}$ also independently influences the $\mathrm{pH}$ of a biological system, its contribution in determining in vivo acid base activity of an IVF is generally regarded to be low as the concentration of dissolved $\mathrm{CO}_{2}$ is itself low (about $0.012 \mathrm{mmol} / 1))^{[2,6,7]}$ But it should be kept in mind that IVFs with high $\mathrm{CO}_{2 \text { Tот }}$ have impact on intracellular acid base status, more during rapid administration or low perfusion states. ${ }^{[6,7]}$ Contrary to the prediction by Singh et al. the $\mathrm{pH}$ of hypertonic saline (3\%) is 5.8 and it causes more acidosis than NS because of its higher osmolarity that draws more water from other body fluid compartments. ${ }^{[6,7]}$ Although the $\mathrm{pH}$ of Hartmann`s solution is 5, its in vivo SID is $27 \mathrm{meq} / \mathrm{l}$, which is close to the ideal SID of $24 \mathrm{meq} / 1^{[2,6,7]}$ And despite its $\mathrm{pH}$ of 5 , it is known to prevent infusion-related metabolic acidosis. ${ }^{[2,6,7]}$ In-depth discussion on application of the concept of quantitative physical chemistry on the in vivo effect of acid base homeostasis is available. ${ }^{[6,7]}$ The effect on plasma $\mathrm{pH}$ by solutions with same $\mathrm{pH}$ may be different and differing $\mathrm{pH}$ can have similar acid-base effects. ${ }^{[2,6]}$ Thus, the effect of an IVF on plasma/ECF SID, $\mathrm{A}_{\text {тот }}$ and $\mathrm{CO}_{\text {2тот }}$ depending on the amount infused should be considered while predicting its possible in vivo effect on acid base status, not merely its in vitro $\mathrm{pH} \cdot .^{[1-7]}$

\section{Priyam Saikia, Dipika Choudhury,} Bikash B. Bora Department of Anaesthesiology and Critical Care, Guwahati Medical College and Hospital, Guwahati, Assam, India

Correspondence: Dr. Priyam Saikia,

Department of Anaesthesiology and Critical Care, Gauhati Medical College and Hospital, Guwahati - 781 032, Assam, India. E-mail: saikia.priyam80@gmail.com

\section{References}

1. Singh PM, Borle A, Trikha A. Are we infusing acids into our patient's blood? Indian J Crit Care Med 2014;18:49-50.

2. Reddi BA. Why is saline so acidic (and does it really matter?). Int J Med Sci 2013;10:747-50.

3. Horváth K, Regös E, Varga S. Comparative testing of titrable acidity degree and $\mathrm{pH}$ value of infusion solutions. Ann Immunol Hung 1973;17:265-8.

4. Gaudry PL, Duffy C, Bookallil MJ. The pH and titratable acidity of intravenous infusion solutions. Anaesth Intensive Care 1972;1:41-4.

5. Bruegger D, Jacob M, Scheingraber S, Conzen P, Becker BF, Finsterer U, et al. Changes in acid-base balance following bolus infusion of $20 \%$ albumin solution in humans. Intensive Care Med 2005;31:1123-7.

6. Morgan TJ. Fluid Resuscitation. In: Kellum JA, Elbers PW, editors. Stewart's Textbook of Acid-Base, $2^{\text {nd }}$ ed. UK: Lulu Enterprises Ltd.; 2009. p. 351-64.

7. Morgan T.J. The meaning of acid-base abnormalities in the intensive care unit: Part III -- Effects of fluid administration. Crit Care 2005;9:204-11.

\begin{tabular}{|l|l|}
\hline \multicolumn{2}{|c|}{ Access this article online } \\
\hline Quick Response Code: & Website: \\
& www.ijccm.org \\
\cline { 2 - 2 } & \\
\hline
\end{tabular}

